ISSN(Online) :2319-8753

ISSN (Print) : :2347-6710

\title{
International Journal of Innovative Research in Science, Engineering and Technology
}

(An ISO 3297: 2007 Certified Organization)

\section{Vol. 4, Issue 10, October 2015 \\ Determination of Reservoir Capacity Using Linear Programming}

\author{
Susom Dutta ${ }^{1}$ \\ U.G. Student, School of Mechanical \& Building Sciences (SMBS), VIT University, Vellore, Tamil Nadu, India ${ }^{1}$
}

\begin{abstract}
Now a day's, computational modeling has gained much importance for the determination of several phenomenon in the field of Hydrology. Artificial intelligence are now being used for prediction of rainfall, runoff etc. This paper depicts that how linear programming can be applied for the determination of reservoir capacity. Reservoir capacity depends on the inflow available and demand where inflow in the river is always greater than the demand, there is no storage required and if the inflow in the river is small but the demand is high, a large reservoir capacity is required. Here, two sets of constraints to be satisfied, one relates to storage continuity and the other to capacity. These two constraints are employed to define the linear equations and to develop the model. To get accurate results evaporation loss is also accounted for constructing the model. After the development of the model, it is analysed using LINGO software in which values of the reservoir are provided and the reservoir capacity is determined.
\end{abstract}

KEYWORDS: Reservoir capacity, mass balance, active storage, dead storage, evaporation loss, linear programming, LINGO.

\section{INTRODUCTION}

A reservoir is a natural or artificial lake, storage pond, or impoundment from a dam which is used to store water. Reservoirs may be created in river valleys by the construction of a dam or may be built by excavation in the ground or by conventional construction techniques such as brickwork or cast concrete. Reservoirs can also be called those water bodies formed or modified by human activity for specific purposes, in order to provide a reliable and controllable resource.

Reservoirs are usually found in areas of water scarcity or excess, or where there are agricultural or technological reasons to have a controlled water facility. Where water is scarce, for example, reservoirs are mainly used to conserve available water for use during those periods in which it is most needed for irrigation or drinking water supply. When excess water may be the problem, then a reservoir can be used for flood control to prevent downstream areas from being inundated during periods of upstream rainfall or snow-melt. Particular activities such as power generation, fish-farming, paddy-field management or general wet-land formation, for example, are also met by constructing reservoirs. By implication, they are also water bodies which are potentially subject to significant human control, in addition to any other impact.

Reservoirs range in size from pond-like to large lakes, but in relation to natural lakes the range of reservoir types and morphological variation is generally much greater. For example, the most regular, and the most irregular, water bodies are likely to be reservoirs. This variability in reservoirs, allied to management intervention, ensures that their 


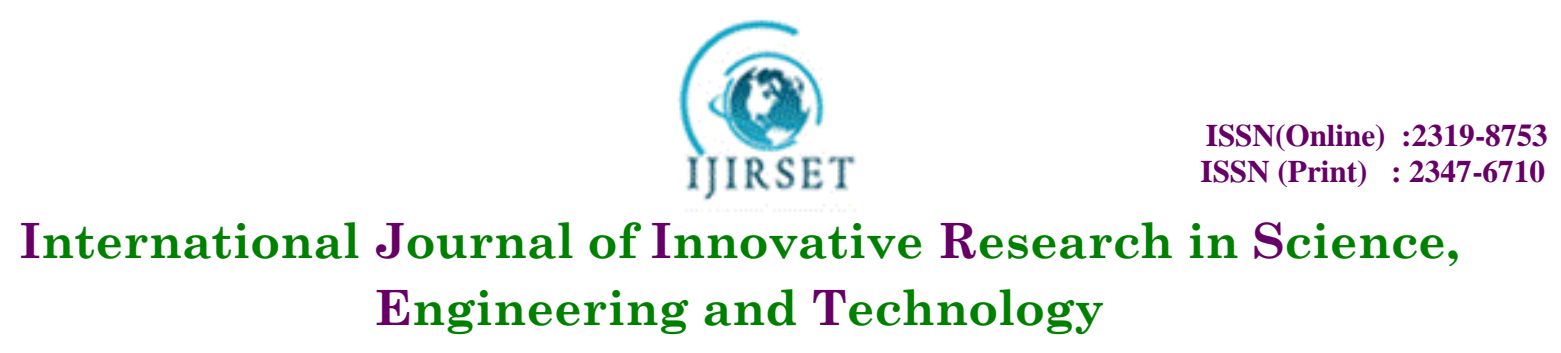

(An ISO 3297: 2007 Certified Organization)

Vol. 4, Issue 10, October 2015

water quality and process be misleading to make any general statements about them without significant qualification as to their type. Reservoirs do, nevertheless, share a number of attributes with natural lakes and some are even riverine in their overall nature. Generally, all reservoirs are subject to water quality requirements in relation to a variety of human uses. The variation in design and operation of control structures in reservoirs can provide greater flexibility and potential for human intervention than in natural lakes (and, therefore, considerable scope for management and control) with the objective of achieving a desired water quality. However, the nature of the intervention or control can complicate the development and operation of water quality.

Yield is the volume of water which can be withdrawn from a reservoir in a specified period of time. Safe yield is the maximum quantity of water which can be supplied from a reservoir in a specified period of time during a critical dry year. Secondary yield is the quantity of water which is available during the period of high flow in the rivers when the yield is more than the safe yield. Average yield is the arithmetic average of the firm yield and the secondary yield over a long period of time. Design yield is the yield adopted in the design of a reservoir. The design yield is usually fixed after considering the urgency of the water needs and the amount of risk involved.

Reservoir capacity depends on the inflow available and demand where inflow in the river is always greater than the demand, there is no storage required and if the inflow in the river is small but the demand is high, a large reservoir capacity is required. The required capacity for a reservoir can be determined by using graphical method or using mass curves and analytical method.

\section{DATASET EMPLOYED}

The reservoir capacities for the given data over 30 years for Gadana dam, Tirunelveli District, Tamil Nadu, India have been employed here.

\section{LINEAR PRGRAMMING MODEL}

An alternative and more elegant method to sequent peak method. There is one assumption that has been taken that is inflows are deterministic. In LP, the linearity assumption simplifies incorporating the evaporation loss function easily into storage continuity relationships.

Two sets of constraints to be satisfied here, one relates to storage continuity and the other to capacity. Let, Rt be the release and Dt the specific demand.

Optimization model for active storage, Ka.

Minimise Ka.

Linear Equations:

Mass balance:

$\mathrm{St}+\mathrm{Qt}-\mathrm{Rt}-\mathrm{Lt}=\mathrm{St}+1$

Maximum active storage:

$\mathrm{St}<\mathrm{Ka}$

Non-negativity:

$\mathrm{St}>0 ; \mathrm{Ka}>0$

Where, 


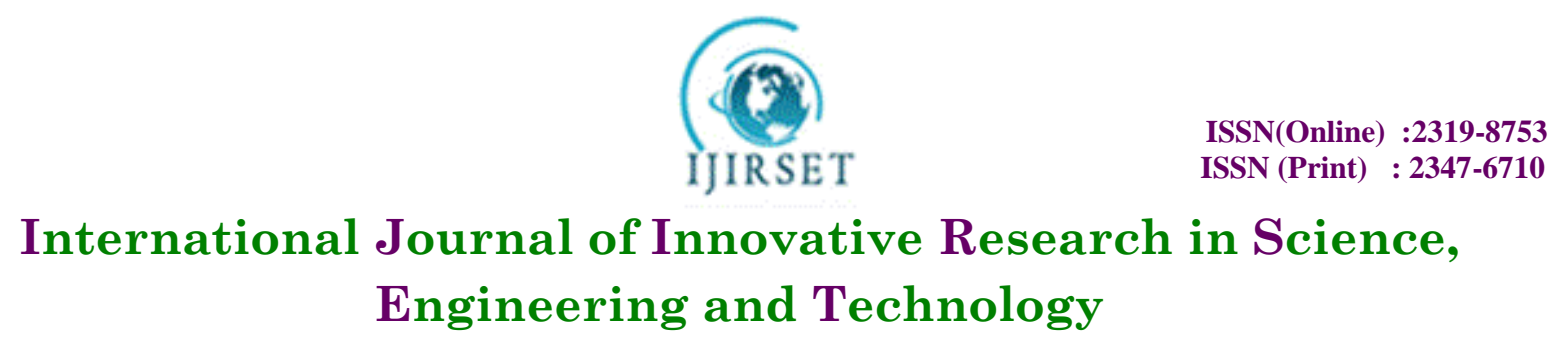

(An ISO 3297: 2007 Certified Organization)

Vol. 4, Issue 10, October 2015

Rt is pre-specified (known) release.

Qt is known inflow.

$\mathrm{Lt}$ is estimated storage loss.

St is storage at beginning of period $t$.

$\mathrm{Ka}$ is active storage capacity.

In this, continuity, with evaporation loss has been accounted.

$\mathrm{Kd}$ is dead storage.

$A_{o}$ is the surface area at dead storage.

$\mathrm{a}$ is the area per unit active storage above $A_{o}$.

Total rate of evaporation in period $\mathrm{t}$ is given by

$E=A_{o} e t+\frac{a(S t+S t+1)}{2 t}$

where

$\mathrm{Lt}$ is the fixed evaporation loss $=$ et $\mathrm{A}_{\mathrm{o}}$.

et is the evaporation rate in period $t$.

$A_{o}$ is water surface area at top of the dead storage level.

$\mathrm{A}$ is the surface area per unit active storage (slope of the area-capacity relationship beyond the dead.

Continuity, with evaporation loss accounted,

$\mathrm{St}+\mathrm{Qt}-\mathrm{Rt}-\mathrm{Et}=\mathrm{St}+1$

Substitute in Et continuity equation,

$\mathrm{St}+\mathrm{Qt}-\mathrm{Rt}-\mathrm{Et}=\mathrm{St}+1$

$\mathrm{Et}=\mathrm{Lt}+\mathrm{at}(\mathrm{St}+\mathrm{St}+1)$

$\mathrm{Lt}=$ et $\mathrm{A}_{\mathrm{o}}$

$\mathrm{St}+\mathrm{Qt}-\mathrm{Rt}-\mathrm{Et}=\mathrm{St}+1$

On solving we get,

$\mathrm{ST}+\mathrm{Qt}-\mathrm{Lt}-\mathrm{Rt}=\mathrm{St}+1$

The storage in each period is bound by the capacity, $\mathrm{K}$, thus

St $<$ K

Also,

Rt $<$ Dt

The reservoir capacity $\mathrm{K}$ is a variable, which must be minimized. The objective is to minimize K.

The model formulation reduces to,

Minimize K,

$(1-\mathrm{at}) \mathrm{St}+\mathrm{Qt}-\mathrm{Lt}-\mathrm{Rt}=(1+\mathrm{at}) \mathrm{St}+1$

St $<$ K

$\mathrm{Rt}<\mathrm{Dt}$ 


\section{。 \\ IJIRSET \\ ISSN (Print) : 2347-6710 \\ International Journal of Innovative Research in Science, Engineering and Technology}

ISSN(Online) :2319-8753

(An ISO 3297: 2007 Certified Organization)

Vol. 4, Issue 10, October 2015

$\mathrm{ST}+1=\mathrm{S} 1$, where

$\mathrm{T}$ is the last period in sequence.

The last constraint means that when considering a sequence of monthly inflows in a year,

$\mathrm{T}=12, \mathrm{~S} 13$ in the formulation is set equal to $\mathrm{S} 1$. The purpose is to ensure that the storage at the end of the last period in the year is same as the storage at the beginning of the first period as the inflow sequence is assumed to be repetitive. In the storage continuity equation, spill, if any in period $t$, is absorbed in the term Rt.

\section{SOFTWARE AND PROGRAMMING USED}

Software used: LINGO 14.0 x64

By LINDO CORP. CHICAGO, IL, USA

LINGO is a comprehensive tool designed to make building and solving Linear, Nonlinear (convex \& nonconvex/Global), and Quadratic, Quadratically Constrained, Second Order Cone, Stochastic, and Integer optimization models faster, easier and more efficient. LINGO provides a completely integrated package that includes a powerful language for expressing optimization models, a full featured environment for building and editing problems, and a set of fast built-in solvers.

\section{STEPS FOR MODEL FORMULATION OF LP IN LINGO}

1. Equality form of constraints:

$(1-\mathrm{at}) \mathrm{St}+\mathrm{Qt}-\mathrm{Lt}-\mathrm{Rt}=(1+\mathrm{at}) \mathrm{St}+1$

The constraint should imply that Rt includes the demand to be met and possible spill in the period. Ensure demand in every period is satisfied in full.

2. Inequality constraints:

Use ' $>$ ' instead of ' $=$ ' and substitute Dt in place of Rt.

$(1-\mathrm{at}) \mathrm{St}+\mathrm{Qt}-\mathrm{Lt}-\mathrm{Dt}>(1+\mathrm{at}) \mathrm{St}+1$

Builds in flexibility to take care of spills. Excess water over demand and evaporation is stored within the reservoir until the capacity. The problem statement is

Minimize $\mathrm{K}$

$(1-\mathrm{at}) \mathrm{St}+\mathrm{Qt}-\mathrm{Lt}-\mathrm{Dt}>(1+\mathrm{at}) \mathrm{St}+1$

$\mathrm{St}<\mathrm{K}$

The spill in period $t$ is

$($ Spillt $)=(1-$ at $) \mathrm{St}+\mathrm{Qt}-\mathrm{Lt}-\mathrm{Dt}-\mathrm{atSt}+1-\mathrm{K}$

...if positive

$=0$

... otherwise

3. Other equality form of constraints:

Specify additional term for spill in each constraint and penalize spills in the equation

$(1-\mathrm{at}) \mathrm{St}+\mathrm{Qt}-\mathrm{Lt}-\mathrm{Dt}-$ Spillt $=(1+\mathrm{at}) \mathrm{St}+1$

Storage yield function: To determine the maximum constant yield (constant release in all periods within a year) from a reservoir.

Formulation is, 


\section{(a) \\ IJIRSET \\ ISSN(Online) :2319-8753 \\ ISSN (Print) : 2347-6710 \\ International Journal of Innovative Research in Science, Engineering and Technology}

(An ISO 3297: 2007 Certified Organization)

\section{Vol. 4, Issue 10, October 2015}

Maximize $\mathrm{R}$

$(1-\mathrm{at}) \mathrm{St}+\mathrm{Qt}-\mathrm{Lt}-\mathrm{R}>(1+\mathrm{at}) \mathrm{St}+1$

and

St $<$ K

with

$\mathrm{ST}+1=\mathrm{S} 1$, where $\mathrm{T}$ is the last period

Mixed integer LP formulation for maximizing yield: An elegant way to solve a problem with equality constraints accounting for spills is by the use of integer variables in LP formulation. Mixed integer formulation ensures that spill will not occur unless reservoir is full.

4. Introduce additional constraints using integer variables:

Constraints may be specified as:

Spillt $<\mathrm{Bt} * \mathrm{M}$

$\mathrm{Bt}<(\mathrm{St}+1) / \mathrm{K}$

bt is integer $<1$

When $\mathrm{St}+1$ is less than $\mathrm{K}$, then

$\mathrm{Bt}=0$ and Spillt $=0$

When $\mathrm{St}+1$ is higher than $\mathrm{K}$, then

$\mathrm{Bt}>1$

Bt is forced to be equal to 1 ( $\mathrm{St}+1=\mathrm{K})$ in order to make spill positive (+ve).

Points to be noted:

- Total annual inflow in all periods is greater than the sum of demands and evaporation losses; otherwise the problem will be infeasible.

- The problem of determining $\mathrm{K}$ for a given $\mathrm{R}$ cannot be solved using mixed integer formulation, the constraint.

$\mathrm{Bt}<(\mathrm{ST}+1) / \mathrm{K}$ or $\mathrm{BT} * \mathrm{~K}<\mathrm{ST}$

Becomes nonlinear when both are variables.

\section{RESULTS AND DISCUSSIONS}

Solution obtained from the above method is $6.0599 \mathrm{Mm}^{3}$.

Thus this software and programming was used to calculate all the reservoir capacities of the given data over 30 years for Gadana dam. 


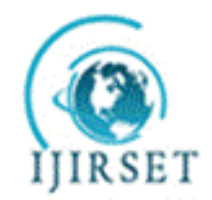

ISSN(Online) :2319-8753

ISSN (Print) : 2347-6710

\section{International Journal of Innovative Research in Science, Engineering and Technology}

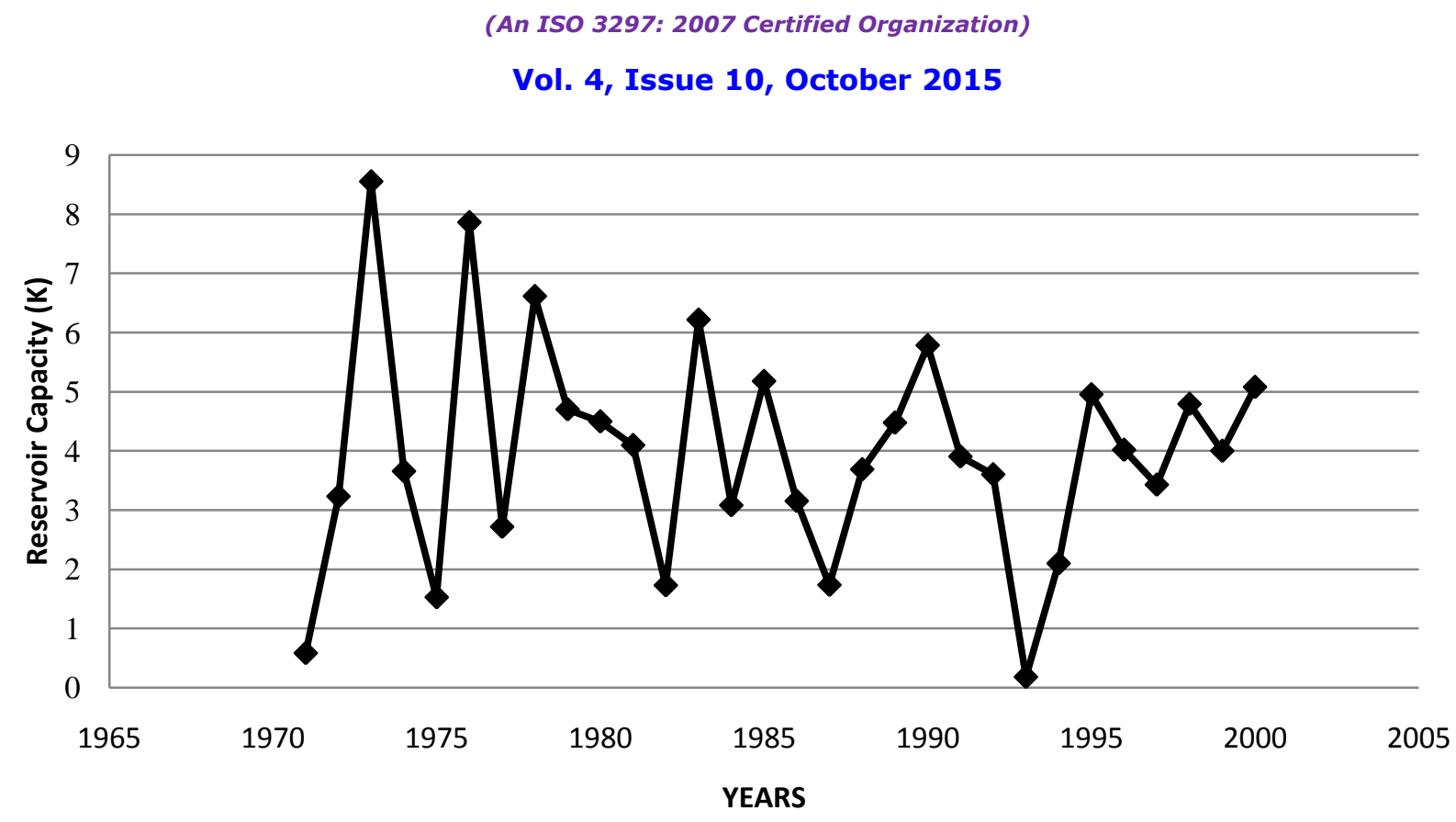

Figure 1, Graph plotted between Reservoir capacity $(\mathrm{K})$ and Years

The above graph shows the value of Reservoir Capacity (K) found using above mentioned method for the 30 years. Through this graph it is easily understood the reservoir capacity corresponding to any year between 1970 to 2000.

Table 1, Reservoir capacity calculated for Gadana Dam in $\mathrm{Mm}^{3}$ for thirty years.

\begin{tabular}{|c|c|}
\hline Years & Reservoir Capacity (K) \\
\hline 1971 & 0.58084 \\
\hline 1972 & 3.229 \\
\hline 1973 & 8.5509 \\
\hline 1974 & 3.655 \\
\hline 1975 & 1.52423 \\
\hline 1976 & 7.8609 \\
\hline 1977 & 2.7153 \\
\hline 1978 & 6.6124 \\
\hline 1979 & 4.7 \\
\hline 1980 & 4.4953 \\
\hline 1981 & 4.0948 \\
\hline 1982 & 1.7264 \\
\hline 1983 & 6.2147 \\
\hline 1984 & 3.0792 \\
\hline 1985 & 5.1771 \\
\hline
\end{tabular}


ISSN(Online) :2319-8753

ISSN (Print) : 2347-6710

\section{International Journal of Innovative Research in Science, Engineering and Technology}

\begin{tabular}{|c|c|}
\hline \multicolumn{2}{|c|}{ Vol. 4, Issue 10, October 2015} \\
\hline 1986 & 3.1505 \\
\hline 1987 & 1.7327 \\
\hline 1988 & 3.6863 \\
\hline 1989 & 4.4751 \\
\hline 1990 & 5.7827 \\
\hline 1991 & 3.9031 \\
\hline 1992 & 3.6005 \\
\hline 1993 & 0.1785 \\
\hline 1994 & 2.0965 \\
\hline 1995 & 4.9534 \\
\hline 1996 & 4.0159 \\
\hline 1997 & 3.4258 \\
\hline 1998 & 4.7899 \\
\hline 1999 & 3.9987 \\
\hline 2000 & 5.078 \\
\hline
\end{tabular}

The value of the Reservoir Capacity (K) obtained for the 30 years which is depicted in the above graph is listed in table 1 .

\section{CONCLUSIONS}

This paper examines the capability of Linear Programming for determination of reservoir capacity. The results obtained from this are then compared with the results obtained using graphical and analytical methods. The comparison resulted as the exact values with minute error. In short, it can be concluded that the developed Linear Programming can be used much beneficially for determination of reservoir capacity.

\section{REFERENCES}

1. Bruk S, "Prediction methods. In: Bruk S (ed) Methods of computing sedimentation in lakes and reservoirs", International Hydrological Programme, IHP-II Project, A.2.6.1.Panel, UNESCO, February, Paris, pp 165-210, 1985.

2. Davis RJ, Koop K, "Eutrophication in Australian rivers, reservoirs and estuaries - a southern hemisphere perspective on the science and its implications", Hydrobiologia 559:23-76, 2006.

3. Evrard J, "Technical and economic impact of reservoir sedimentation. In: Bruk S (ed) Methods of computing sedimentation in lakes and reservoirs", International Hydrological Programme, IHP-II Project, A.2.6.1.Panel, UNESCO, February, Paris, pp 1-10, 1985.

4. Furnans J, Austin B, "Hydrographic survey methods for determining reservoir volume", Environ Model Softw 23:139-146, 2008.

5. Graf WL, "Downstream hydrologic and geomorphic effects of large dams on American rivers", Geomorphology 79:336-360, 2006.

6. Palmieri A, Shah F, Dinar A, “ Economics of reservoir sedimentation and sustainable management of dams", J Environ Manage 61:149163, 2001.

7. Rakhmatullaev S, "Geoinformation systems for estimation of reservoir volume capacities due to sedimentation (in Russian)", In: Final Proceedings of IV Conference, Specialist who studied abroad, Uzbekistan President Foundation ISTEDOD, Vol.XI, Tashkent, Uzbekistan, November 24-25, pp 40-51, 2006.

Websites: 


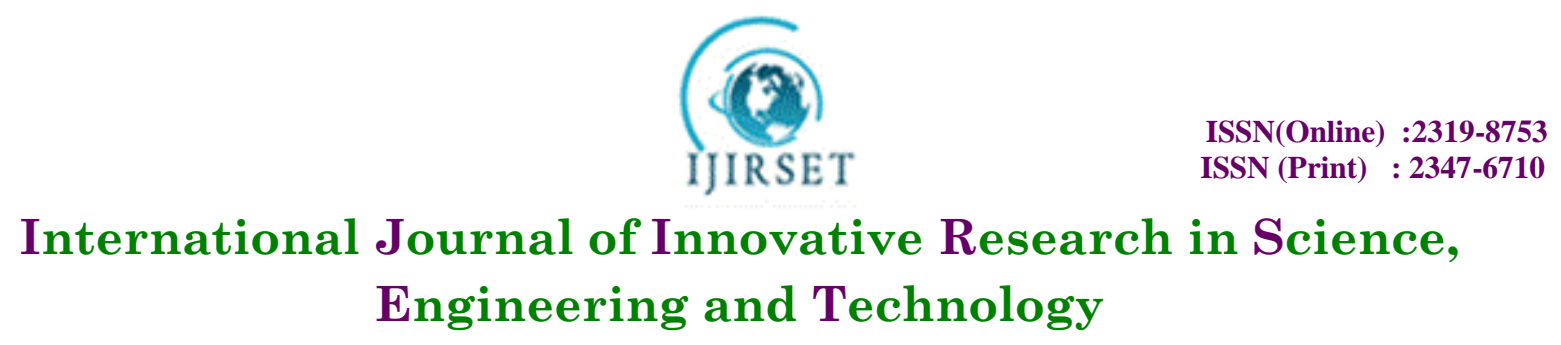

(An ISO 3297: 2007 Certified Organization)

Vol. 4, Issue 10, October 2015

http://www.mdba.gov.au/river-data/current-information-forecasts/river-flows

http://en.wikipedia.org/wiki/Reservoir

http://www.academia.edu/585875/Water Management and Reservoirs in India and Sri Lanka

http://www.lingolearn.com/ 